\title{
Philosophy and Ataraxia in Sextus Empiricus
}

PASCAL MASSIE / Oxford, OH /

This essay is concerned with two interrelated questions. First, a broad question: in what sense is Skepticism $a$ philosophy - or in what sense is it "philosophy" (as we will see, these are not identical questions)? Second, a narrow one: how should we understand the process whereby ataraxia (freedom from disturbance) emerges out of epoche (suspension of judgment)? The first question arises because Skepticism is often portrayed as anti-philosophy. This depiction, I contend, surreptitiously turns a Skeptical method into a so-called Skeptical doctrine which is then either condemned for being self-refuting or salvaged as a plausible (albeit odd) epistemological theory. Instead, I argue that Skepticism is not so much a philosophy that has a worldview to proclaim as it is a philosophy that invites us to perform something. And more precisely, Skepticism invites us to perform a three-stage exercise: equipollence, epoche, and ataraxia.

However, the connection between these stages (in particular between the last two) is problematic: what guarantees that ataraxia will follow epochē? Prima facie, one would assume that the link between these terms should be inferential or causal. Yet, Sextus simply connects these moments with the laconic terms "first" and "afterwards." Moreover, causality and logical inferences are objects of lengthy and meticulous critiques that prevent Sextus from arguing that ataraxia is caused or entailed by epoche.

These two initial questions are so intertwined that Sextus conflates the account of the transition from epoche to ataraxia with the account of how some "thinkers of old" 
became Skeptics. To be an accomplish Skeptic is to experience ataraxia while continuing to investigate. Thus, an answer to the question: "How do we attain ataraxia after epochēe" contains an answer to the question "What is Skepticism?" Yet, Sextus main clue, the story of Apelles the painter who discovered how to create a likeness of a horse's lather by throwing his sponge on the wall, is far from transparent.

Two major difficulties confront us: First, Apelles eventually achieves the visual effect he desperately strove for by throwing his sponge against the wall. Yet, he did not do so in order to produce a particular effect. Instead of demonstrating a causal or an inferential relation (a relation where the antecedent is the cause or the reason of the consequent), the story of Apelles disconnects the moments of Skepticism. The goal is achieved without intention. At best, then, epoche would provide an occasion, a space where freedom from disturbance may occur. Second, if ataraxia can be achieved without enlightenment, why does the Skeptic continue philosophizing? I contend that this is possible if, for the Skeptic, philosophy is not instrumental. The chain of reasons whereby inquiry leads to enlightenment which in turn culminates in ataraxia is broken. The attainment of wisdom remains fundamentally undecided; inquiry is not a mean anymore and it can be pursued free from disturbance. In the compound word "philo-sophia" the Skeptics stress the first part: inquiry is intrinsically valuable; so much so that the investigation not only scrutinizes any dogmatic assumptions, but also turns the same uncompromising gaze on itself.

Lastly, I suggest that the Skeptic's path is not a matter of epistemological investigation but a path of self-discovery. The Skeptic must learn to dissociate herself from the thoughts she entertains. The plane of unrelenting inquiry and the plane of ataraxia can coexist because the Skeptic has discovered that her consciousness is distinct from its intentional content now bracketed by epochē. Skepticism is a philosophical practice of a certain dialectical method but also a practice upon oneself. To free ourselves from our attachment to dogmatic beliefs is to open up a space of self-detachment.

\section{Is Skepticism Anti-Philosophy?}

The existence of Skepticism in the history of philosophy is the existence of a scandal. Is Skepticism philosophy? Is it ' $a$ ' philosophy? Insofar as it is concerned with truth, Sextus Empiricus claims that Skepticism counts as one of the three "most fundamental kinds of philosophy" (PH. I 4). Skepticism would, therefore, be philosophy. Sextus avoids, however, calling it a school or sect (hairesis) and talks about it as a "movement" (agōgē).

1 The word agōē has various meaning, as R. G. Bury mentions in a note of the Loeb edition of Sextus Empiricus (Volume I 2, note b). Although he opts for "doctrine" in his translation, Bury remarks that agoge connotes the idea of "leading." For their part, Annas and Barnes chose "persuasion." Both "persuasion" and "doctrine," however, are inappropriate because they presuppose a dogmatic content; "doctrines" are taught (doctrina) because they are held to be true and "persuasion" is an unshakable conviction. Yet, in this essential passage Sextus explicitly distinguishes Skepticism from the Dogmatic and the Academic kinds of philosophy precisely on the ground that the Skeptic engages in philosophy without being persuaded by any doctrine. Thus, to translate agōgē by persuasion 
The vagueness of this qualification reveals a difficulty: if we conceive of the history of philosophy as a history of doctrines, then Skepticism is not a philosophy since it cannot, by definition, be construed as a doctrine. The very idea of a skeptical doctrine, dogma or system is incoherent. Should the Skeptic speak the truth, she would immediately contradict herself since her claims would fall under the heading of dogmatism which is precisely what Skepticism is meant to rule out.

This ambivalence still reverberates today. Insofar as it belongs to the history of Hellenistic philosophy, historians do treat Skepticism as a "kind" of philosophy that is identifiable by virtue of its quasi-doctrine. There are, after all, recognizable features that distinguish it from Stoicism and Epicureanism. Yet, this quasi-doctrine is often perceived as an anti-doctrine in opposition to which philosophy must be defined. According to that view, not only is Skepticism not philosophy but whoever assents to it (if such a thing is even possible) has ipso facto renounced philosophy. It is as if philosophy must assert itself by rejecting Skepticism, just as earlier the Platonists defended it by confronting the Sophists. As a consequence, philosophy, if it must address Skepticism, should do so with the intention of refuting it. Thus, Skepticism is both included and excluded from philosophy. ${ }^{2}$

One can even go a step further and suggest that philosophy does not even have to engage Skepticism at all. It is sufficient to reject it in principle. In Philosophical Dialectic Nicholas Rescher (2006:3) argues that Skepticism violates the first principle of "informative adequacy" which states (borrowing the formulation from C. S. Pierce): "never bar the path of inquiry... never adopt a methodological stance that would systematically prevent the discovery of something that could turn out to be true". As a consequence, concludes Rescher, radical Skepticism must be excluded from philosophy since "if we adopt this line... all progress is blocked from the very outset." Insofar as it seems to reject the parameters that constitute a philosophical debate, Skepticism would not even be worthy of a refutation; it has already placed itself outside the sphere of debate. Thus, it appears that philosophy must either refute or exclude its ominous other: Skepticism. And yet, a careful reading of Sextus Empiricus' Outlines shows that many of the common charges against Skepticism dismiss it too easily by turning it into a rather outlandish position that is not to be found in Sextus' writings.

The short but influential volume edited by Burnyeat and Frede (1997) illustrates the fact that most of the scholarship has focused on the possibility (or impossibility) for the Skeptic to believe and to act. Briefly, there are two fundamental lines of objections. First, it is claimed that Skepticism contradicts itself. Since a genuine Skeptic cannot profess a doctrine or propound a system, ultimately she cannot say anything; she cannot articulate what she means to say since whatever she could say is in advance (and by her own

or doctrine is to introduce a contradiction where there is none. I therefore opt for the term "movement" which preserves the active sense of agōē and conveys the performative dimension of skeptical thinking.

${ }^{2}$ Laursen (2009: 153) has suggested a parallel with Cynicism: "It might be argued that Cynicism is not a philosophy but an anti-philosophy, and up to a point that is true. The same can be said of Skepticism, especially in the Pyrrhonian variety; yet, both varieties are included in the anthologies of Hellenistic debates." 
logic) condemned to be unintelligible. In other words, it seems that Skepticism falls into a situation analogous to the liar's paradox and cannot avoid being self-defeating. ${ }^{3}$ Second, it has been argued that Skepticism is incompatible with life. One simply cannot live without depending on some belief. ${ }^{4}$ The reason why I do A rather than B, get up in the morning rather than stay in bed, grade students' papers rather than burn them in the fireplace is that I have some beliefs that guide my actions. If an unexamined life is not worth living, a life without beliefs, on the other hand, is simply unlivable. On pragmatic grounds, if we were to follow the Skeptics, we would find ourselves in a situation analogous to Buridan's ass, standing at equal distance between a stack of hay and a pail of water, being equally hungry and thirsty; yet unable to decide whether to eat or drink first and ending up dying of starvation and thirst. These objections have a long history. In Cicero's Academica Lucullus, speaking on behalf of the Stoics, already argued that akatalêpsia (the denial of katalêpsis, or assent to graspable, cognitive impressions) is self-refuting and that it prevents certain actions, particularly virtuous ones (Ac. 2. 19-27, 32-33).

However, a careful examination of the extant texts shows that Sextus is acutely aware of these objections and has a few things to say in response. ${ }^{5} \mathrm{With}$ respect to the first one (self-contradiction), it is precisely because Sextus wants to construe Skepticism in an absolutely non-dogmatic fashion that he keeps open the very possibility that Dogmatism could, in principle, be right (the dogmatic philosophers, despite their pretenses, have not found the truth yet). Thus, a coherent Skeptic does not maintain that there is no truth nor that truth cannot be found. As Charlotte Stough (1984: 138) put it: "the Skeptic's speech properly construed has no truth value. The dogmatist's assertions have a truth value but cannot be established as true or false". However, if Dogmatism has failed so far, this is no reason to rule out the possibility of its eventual success. ${ }^{6}$ It is the Academics (at least according to Sextus) who commit the modal fallacy of inferring impossibility -we cannot know- from a premise that simply states a (negative) actuality- we do not know.

There is something noble and praiseworthy in the Dogmatist's endeavor to discover an apodictic truth on the basis of which human life could be grounded. The Skeptic's suspicion, however, is that this goal has not been reached. This is a de facto, not a de jure

3 This issue has been recently revisited by Castagnoli (2010) and Wersinger and Perceau (2010).

${ }^{4}$ Burnyeat (1980) attempts to give support to this line of objection already found in Hume's famous remark: "the first and most trivial event in life will put to flight all his [the Pyrrhonist's] doubts and scruples, and leave him in the same, in every point of action and speculation, with philosophers of every other sect" (An Enquiry Concerning Human Understanding, Section XII). Recently, Vogt (2010) has proposed a defense of the Skeptic's position by showing how a Skeptic can engage in action.

${ }^{5}$ Defenses of Sextus Empiricus have been presented by, among others, Bailey (2002), Johnsen (2001), Wersinger and Perceau (2010) and Brennan (1999).

${ }^{6}$ In this context, the term "dogmatist" does not designate an arrogant individual who makes unsubstantiated claims. Although this connotation is most likely also implied, a character flaw is not the heart of the matter. Rather, "in the proper sense of the term, those who are called Dogmatists think that they have discovered the truth” (PH. I 3).

${ }^{7}$ Does the Pyrrhonian skeptic really believe that the goal can be reached or is she not committed to the view that sophia is in principle unattainable? Gisela Striker (2001: 121) has argued for the second option: "philosophi- 
claim. But while the Skeptic can entertain the thought that the Dogmatist's goal can be reached, the other way around is not true: a Dogmatist cannot admit the possibility of Skepticism without renouncing her Dogmatism. By claiming that they have reached sophia (or at least have found the way to it) the Dogmatists wish to halt the inquiry. This imbalance is crucial; Pyrrhonian Skepticism does not claim that knowledge is impossible; if it were to do so it would become a form of negative dogmatism which is dogmatic nonetheless. ${ }^{8}$ The point of Skepticism is not to stop inquiry but on the contrary to free inquiry by preventing it from falling into Dogmatism. "The Skeptics are still investigating" (P.H. I 3). The very word "Skeptic" names one who inquires, one who is searching and looking out (skeptesthai). We are so used to identifying "Skepticism" with crude disbelief that we do not pay attention to the fact that the word itself talks of research and inquiry. "The skeptical movement is also called investigative, from its activity in investigating [skeptesthai] and inquiring" (P.H. I 7). Strictly speaking, "Skepticism" is used in contrast to the assumption that one has found definite and definitive knowledge and that, as a consequence, one needs not inquire any further. By stressing from the beginning the literal meaning of skeptikos, Sextus provides a reason why it, more than any form of Dogmatism, should deserve the name of philo-sophia. ${ }^{9}$ No doubt, some people think that philosophy is a waste of time, but these people are not Skeptics.

As for the second objection (incompatibility with the demands of life that presuppose adherence to some beliefs) Sextus readily admits that we obviously cannot act and make choices without entertaining some thoughts to which we acquiesce. The legend of Pyrrho never guarding against anything, "encountering anything, even wagons, precipices and dogs and everything of that sort; committing nothing whatever to his senses," as Diogenes Laertius reports, is just what it is; namely, a legend (Diog. Laert. IX 3).

When we say that the Skeptic does not hold beliefs, we are not using 'belief' in the broad sense in which some say that belief is acquiescing in something; for the Skeptic assents to the conditions forced on him in accordance with an appearance... Rather, we say that the Skeptic does not hold beliefs in the sense in which some say that belief is assent to some non-evident matter investigated by the sciences. For the Skeptic does not assent to anything non-evident (P.H. I 13).

cal investigations seem to be precisely what the Skeptic way of life is designed to avoid". This would entail that Sextus' own characterization of Skepticism ("The Skeptical movement is called investigative from its activity in investigating and inquiring." I 7) is either erroneous or deceptive. In the last section of this essay I come back to this issue.

${ }^{8}$ It is most probable that the academic philosophers themselves were not upholding such a naïve form of negative Dogmatism.

9 Sextus never considers the Academic philosophers to be authentic "Skeptics". The modern expression "Academic Skepticism" was well established by the time of David Hume; however, Sextus does not assimilate them to what he considered to be Skepticism proper (i.e., Pyrrhonism). The denial of knowledge (the claims: "we cannot know," or "the attainment of knowledge is impossible") is intrinsically as dogmatic as the contention to actually possess the one doctrine that embodies the truth. 
The problem is not that we cannot avoid having beliefs; it lies in the type of beliefs and in the attitude we have toward them.

\section{Skepticism as Process and Practice}

I would like to propose a departure from the interpretative tradition best exemplified by the works of Frede and Burnyeat (1997) by recasting the debate about beliefs and dogmas within the framework of a conception of philosophy as praxis. We started by noticing that although construed as a determinate philosophical movement, Skepticism is also simultaneously viewed as extraneous or even opposed to philosophy. We need to step back and investigate what leads to this evaluation. I suspect that the difficulty lies not only in the subject matter itself but in our unquestioned assumption according to which philosophy is a matter of constructing doctrines and that its history must be a portrait gallery of systems. The first lesson we can learn from the Skeptics is that we should be wary of this assumption. One could demonstrate the possibility of a Skeptic way of life simply by living it. Hadot (2002: 142) has suggested that "with Skepticism, the distinction between philosophy and philosophical discourse reaches an extreme point". On this account, the Skeptic would have abandoned philosophical discourse in favor of philosophy as a way of life. Her answer to the challenge of justifying herself would not be a matter of defending a thesis with supporting arguments, but a matter of deeds and ethos. Even if it were so, there would still be a huge difference between not professing a doctrine (i.e., not being "dogmatic" in Sextus' sense of the term) and having nothing to say at all. One can still have plenty to say by showing, acting, and being. Could not philosophy occur outside of systems, doctrines, and dogma? Could it not occur as a descriptive account as Sextus suggests we should read him? According to $P H$ I 5-6, the Outlines do not argue for Skepticism but simply offer a description, a report. While it is true that the Outlines are highly argumentative, the arguments are framed within a narrative and Sextus' own discourse is better construed not as a defense but as a report on Skepticism. The Outlines stand one step removed from its conceptual content. This strategy is not merely a matter of form of discourse, it exemplifies and performs Skepticism.

But Sextus can still offer arguments of some sort. Although the Outlines cannot be a direct defense of Skepticism, its arguments constitute a strategy of critical intervention within the very display of dogmatic doctrines. If there cannot be a dogmatic system of Skepticism on pain of contradiction, there is a process, a skeptical modus operandi that advances through specific steps when faced with dogmatic claims. Skeptical philosophy is best understood as s dialectical performance and this is why Sextus characterizes Skepticism by its method:

Skepticism is an ability [dunamis] to set out oppositions among things which appear and are thought of in any way at all, an ability by which, because of the equipollence in the opposed 
objects and accounts, we come first [proton] to suspension [epochē] and afterwards to freedom from disturbance [to de meta touto eis ataraxian] (PH. I 8).

A Skeptic is not identified by the view she holds but by the way she thinks. In the absence of a doctrinal content, Skepticism still retains a specific identity that prevents us from confusing it with other competing Hellenistic schools, but this identity is determined by the specificity of a procedure. To be a Skeptic is to practice a three-stage process: equipollence, epoche $\bar{e}$, and ataraxia. This invitation to philosophize in a certain manner should not surreptitiously be translated into a dogmatic claim.

To describe Skepticism in terms of ability [dunamis] is to stress its practical aspect. Skepticism is not so much a philosophy that has something to say, as it is a philosophy that invites us to do something. A practice cannot be interpreted as a belief system since what matters is not so much what it says as the effects it produces. ${ }^{10}$ If this is correct, then we cannot evaluate Skepticism as if it were a doctrine; rather, we must observe what is being performed. Although the Skeptic acknowledges that she does not possess an assured insight into the nature of things and that, for all she knows, the truth about beings remains shrouded, her practice is not arbitrary. The performative characteristic of Sextus' text suggests that, in the absence of a determined criterion for truth, the Skeptic can still justify herself by inviting her audience in what we could call an experiential verification of her descriptive report. The repetition of formulas such as "we are only saying how things appear to us" (PH. I 190) or the fact that the modes are presented as what the Skeptics "offered" [paradidoasi] (PH. I 164) encourage us to engage in the same activity and see if it yields the same results. This, however, is not equivalent to saying that experiential verification $i s$ the criterion of truth or that the world of appearances is the measure of what is.

Although Sextus retains the Stoic distinction between theoretical and practical philosophy, the emphasis is on the manner of engaging these issues. The distinction between theory and praxis is a distinction between subject-matters but in both cases philosophy is a certain kind of activity. ${ }^{11}$ Even theoretical philosophy is praxis insofar as it is a matter of doing philosophy and conversely, when philosophers argue about ethics they are concerned with theoretical questions about virtue and the good life. The shift that occurs with the emergence of Skepticism is thus not only a matter of privileging

\footnotetext{
${ }^{10}$ Vogt has also insisted on the practical aspect of Skepticism but in a very different sense and for totally different reasons. Appealing to "forced assents" which are entirely passive and "involuntary assent" which "involve a degree of activity," she concludes (2012: 663) that "the Skeptic is far from rejecting appearances; she lets herself be guided by appearances. Appearances are a practical criterion. They are allowed to exert their guiding force only in action". The kind of actions Vogt has in mind, however, is limited. Not committed to the dogmatic claim that honey is sweet the Skeptic will nevertheless follow appearances to make her breakfast (example after Vogt 2012: 660). I am concerned, on the contrary, with philosophical praxis, investigating, engaging in debates, setting up oppositions; that is to say with Skepticism itself as a kind of action that is neither passive nor involuntary.

11 "The ethical part of philosophy is thought to deal with the distinction among fine, bad, and indifferent things" (P.H. III 168).
} 
philosophy as a way of life, as Hadot suggests, but more importantly of proposing a method for engaging theoretical questions by submitting them to a rigorous test. It is therefore essential to understand not only the three stages of equipollence, epoche $\bar{e}$, and ataraxia but also what links them, a connection Sextus tersely indicates by the terms "first" and "afterwards."

The first task is to set up an appearance against another appearance, a belief against another belief or an appearance against a belief. Equipollence occurs when there is "equality with regard to being convincing or unconvincing: none of the conflicting accounts takes precedence over any other as being more convincing” (PH. I 10). In equipollence none of the claims under consideration are refuted. As Brennan (1999: 80) notices, "perhaps further searching will lead to the conviction that the Stoics are right after all; at any rate, none of the arguments against the stoic view have persuaded the Skeptic of its negation either; he is neither persuaded not dissuaded". Epochē and ataraxia seem to result from equipollence. Epochē is described as "a standstill of the intellect owing to which we neither reject nor posit anything" (idem). Finally, ataraxia indicates "freedom from disturbance or calmness of the soul" (idem). Thus, ataraxia is not a subject matter for ethics narrowly construed as a subdivision of philosophy; it is a concern for Skepticism qua philosophy.

It is significant that the first step, equipollence, is not something we simply find out there but something that needs to be set up. One may wonder when, in fact, we find actual equipollence. For the most part when we are facing an alternative, some branch seems more plausible than the other. Yet, this is not an objection, for Sextus acknowledges that this is indeed how we live and act. As soon as we act we follow what seems the best course of action, what seems likely to yield the results we seek or appears to present the most plausible account we can think of. ${ }^{12}$ If it were not the case we would be paralyzed. Thus, the Skeptic does not reject appearances:

We do not overturn anything which leads us, without our willing it, to assent in accordance with a passive appearance- and these things are precisely what is apparent. When we investigate whether existing things are such as they appear, we grant that they appear and what we investigate is not what is apparent but what is said about what is apparent; and this is different from investigating what is apparent itself" (PH. I 19).

The assumption that being and seeming are not identical, that being might be quite different from what appears is not rejected. Skepticism does not embrace appearances

\footnotetext{
${ }^{12}$ Vogt (2010: 177) offers a convincing description of what it could mean to live a Skeptical life: "The Sceptic's response, which tradition portrays as radical, might in fact depict a much more plausible way of life- a life in which there is ample room for customary, learned action, and in which agents do not actually see themselves as fully accountable for their actions, and do not act with the conviction that their actions are what should be done". She (2012: 663) seems, however, to reduce this activity to "passive assent to practically relevant appearances". This is insufficient to give an account of Skepticism as philosophical praxis.
} 
or regard them as "true reality." Although we must suspend judgment as to whether $\mathrm{x}$ truly is $\mathrm{p}$, it still remains that $\mathrm{x}$ appears to have the property $\mathrm{p}$. Appearances command our assent; under normal conditions honey appears sweet and there is no point in trying to deny this. Instead, the Skeptic questions our attempts to establish the truth about whatever ultimate reality lurks beyond appearances. ${ }^{13}$ Even when it is about two conflicting appearances, equipollence bears on the competing dogmatic claims that attempt to address the nature of the purported fundamental reality that underlies these appearances. Sense-perception itself is never purely indifferent; as Sextus puts it, "it leads us to assent" and this is why we act on the ground of these very appearances. If we remain strictly at the phenomenal level, there is rarely equipollence; it is in the nature of appearances to incline us. Epochē is therefore not universal: "you must remember that we do not use these [skeptical] phrases about all objects universally, but about what is unclear and investigated in dogmatic fashion, and that we say what is apparent to us and do not make firm assertions about the nature of externally existing things" (PH. I 208). However, we should not conclude from this that the Skeptic, as would a naïve empiricist, simply accepts appearances as a measure of truth: to grant that appearances incline us is not to grant any alethic claim. Under normal conditions, honey seems sweet, under pathological conditions it doesn't: both are sense-perceptions and there is equipollence between the corresponding dogmatic claims concerning what is not apparent. The equipollence itself, however, is not an experiential datum, it must be set up (something a naïve empiricist never does); doing so is meant to remind us that the inclinations we receive from senseperception do not warrant any claim about the intrinsic nature of what we experience.

\section{Signs and Transition}

Now if, as I suggested, Skepticism is better construed as practice, if its so-called "definition" at the inception of The Outlines designates a method rather than a doctrinal content, then the articulation between these steps becomes both crucial and problematic. Sextus simply talks of "first" and "afterwards," leaving unexplained how we should understand the links in the skeptical process. What, if anything, guarantees that ataraxia will follow epochēe Prima facie it seems that in Sextus' schema equipollence constitutes the basis out of which both epoche and ataraxia arise, with the last instance (ataraxia) itself deriving from the second one in a continuous diachronic progression: Equipollence $\rightarrow$ epoch $\bar{e} \rightarrow$ ataraxia. If so, one is likely to assume that the " $\rightarrow$ " must be either inferential (i.e., if equipollence then epochè or epochè entails ataraxia) or causal (i.e., equipollence is the cause of epoche which, in turn, causes ataraxia or ataraxia is the final cause for which both equipollence and epochē are posited). issue.

${ }^{13}$ Bailey's (2002: 148-165) discussion of Burnyeat's interpretation provides an important insight into this 
Yet, any account of the transition among these three terms is problematic for an inherent reason: causality and logical inferences are objects of lengthy and meticulous critiques. Sextus' discussion of causality is structurally similar to his discussion of arguments and demonstrations: in both instances either we are led into infinite regress or we must posit a cause that has no cause and a reason that is without reason. ${ }^{14}$ Sextus treats inferences and causal relations as two aspects of what I will call a logic of signs. The Skeptic semiotics (which is mostly discussed in PH. II, 10 and Adversus Mathematicos, 8) opens with the claim that signs are what we rely upon when we attempt to apprehend what is non-manifest (whether it is so by nature or simply because the object under investigation is not available at the moment) and it is this semiotics that leads to the discussion of proofs and deduction. Sextus' language here echoes the beginning of his analysis of causality which declares that "causal explanations are all concerned with what is unclear" (PH. I 181). Thus, whether we attempt to demonstrate or to explain causally we are dealing with signs for in both instances we link the visible to the invisible, the manifest to the non-manifest (adelos). Causal or demonstrative arguments seek something that is not apparent and in so doing they turn the manifest, the phenomenal, into a sign that points beyond itself to the non-manifest. In some instances, the non-manifest may have been previously observed together with the thing that is now manifest (i.e., at some point we had one impression of two things). In such cases what is currently non-manifest is simply what is not currently available for perusal. One thing becomes a sign of the other when its presence points to an absent second term. This is a "recollective" (or "commemorative") sign and Sextus has no objection to it for "it is found convincing by everyday life: seeing smoke, someone diagnoses fire; having observed a scar, he says that a wound was inflicted" (II 102). There is, however, a much more problematic kind of sign. What is dubbed an indicative sign "signifies that of which it is a sign not by having been observed evidently together with the thing it signifies but from its proper nature and constitution, as bodily movements are signs of the soul" ( $P H$. II 101). Thus, in Stoic logic a pre-antecedent statement in a sound conditional can be understood as an indicative sign that is revelatory of the consequent..$^{15}$ Implications can then be treated as semiotic relations. This makes of the pre-antecedent an indicative sign, that is, a sign "in its proper nature and constitution." Such a sign would indicate something by itself, without prior association with the thing it signifies, and for Sextus there is no such thing.

Epochē is neither the logical pre-antecedent of ataraxia nor its cause. Thus, the transition from epochè to ataraxia (whether construed in terms of causality or inference) can only be a matter of recollective signs. When Sextus says that ataraxia follows epochē, he can only be reporting an observation of how things happened. It is true that prior to

\footnotetext{
${ }^{14}$ Particularly Book I chapter 17, Book II Chapters 12 to 14, and Book III chapters 4 and 5.

${ }^{15}$ Note that the instance of the soul and the bodily movements is a matter of causal explanation (the body moves because it is animated by the soul) while the second deals with deduction. This further confirms that both cases are subsumed under a "general logic of signs."
} 
investigation, ataraxia functioned as a final cause (it was the goal, the desired end for the sake of which the Skeptic started investigating); but the fully developed method of Skepticism (i.e., the articulation of the three above-mentioned moments) actually dissociates them: epoche is not the means to ataraxia. We know that what we are seeking must (a) allow for a narrative account that resists dogmatic construal and (b) describe the enquirer's intellectual conversion. Thus, the movement of thought between the three key moments of skeptical reasoning (insofar as it can be expressed semantically) can only be recollective. Sextus recalls that the Skeptics of old encountered ataraxia at the occasion of their practice of epoche, but he does not and cannot argue that ataraxia is caused or entailed by epoche. Although narrative accounts follow a chronological order, as the post hoc ergo propter hoc fallacy shows, chronology is no proof of causality. All a Skeptic can say is that one term has been observed to follow the other. The Skeptic does not derive ataraxia from epochē; she happens to encounter it.

The introduction of this haphazard moment undermines any claim to the effect that Pyrrhonian Skepticism is a better choice than dogmatism. Epicureanism, Stoicism, and the Academic school represent various attempts of Hellenistic philosophers to reach ataraxia and, initially at least, the competition to obtain the allegiance of followers must have entailed showing why one's school is a better candidate than the others at securing the prize of a life free of disturbance. This, however, is now ruled out; the Skeptic may still criticize the pretenses of the competing schools, but she cannot pledge that those who embrace Skepticism will enjoy a life free of disturbance. On the ground of past experience, all she can say, at best, is that those who did so in the past have been found to have experienced ataraxia.

A further problem arises at this junction: in accordance with the proper meaning of "Skepticism," to practice epoche and experience ataraxia does not amount to giving up the inquiry. On the contrary, "the skeptical movement [....] puzzles over and investigates everything" (HP I 7). The suspension of judgment must therefore cancel dogmatism without cancelling the possibility that dogmatism could, in principle, reach a truth beyond appearances. Sextus' strategy cannot resemble Kant's resolution of the antinomies by appeal to the "practical interest of reason." ${ }^{16}$ From a skeptical standpoint, the noumenal order (the non-manifest i.e., the real insofar as it does not appear) designates a pole of fundamental neutrality; it can neither incline in one direction nor in the other. This point is carried by a key phrase of Skepticism: "no more this than that" which expresses an equipollence that ends up in equilibrium (HP I 188-191). Noumenal neutrality occurs at two levels: first, since we are inquiring about the non-manifest, the hidden side of

\footnotetext{
16 "A certain practical interest in which every right-thinking man, if he has understanding of what truly concerns him, heartily shares. That the world has a beginning, that my thinking self is of simple and therefore indestructible nature, that it is free in its voluntary actions and raised above the compulsion of nature, and finally that all order in the things constituting the world is due to a primordial being, from which everything derives its unity and purposive connection - these are so many foundation stones of morals and religion. The antithesis robs us of all these supports, or at least appears to do so." Critique of Pure Reason, Antinomy of Pure Reason, $\$ 3$ The Interest of Reason in these Conflicts.
} 
the phenomenal, one cannot claim that it is more this than that. The noumenal order is epistemologically neutral. At a second level, I can neither claim that there is a hidden reality beyond the realm of appearances, nor deny it. The noumenal order is ontologically neutral. The noumenal world remains silent, revealing no more this than that about itself; neither what it is, nor even whether it is. Of course, even this very claim can only indicate how the situation appears at this point. "When we utter the phrase 'in no way more' we are not affirming that it is itself certainly true and firm: here too we are only saying how things appear to us" (HP I 191).

If, as the modes of Agrippa suggest, proofs and arguments end up either begging the question or in infinite regress, we are led to suspect that behind all dogmatic claims lurks a choice which, at bottom, is arbitrary. As PH II 4 argues, the determination of what the standard of truth is, is undermined by the very fact that there is a dispute as to whether there is a standard in the first place (some, like the Stoics, asserting that there is one, others, like Xeniades of Corinth or Xenophanes of Colophon asserting that there is none). To resolve this second-order dispute, we would have to possess an agreed-upon standard, but in order to have such a standard the dispute would have to be resolved. "Thus, the argument falls into the reciprocal mode and the discovery of a standard is blocked" ( $P H$ II 20). Once again, Sextus' point is not to claim that there is no standard of truth but to interrogate the very possibility of resolving the question by raising it at a second-degree level. Although Sextus does not develop the consequences of this argument, the least we can say is that the specter of arbitrariness casts some doubt as to why a thinker embraces one school of thought rather than another. Although a trained philosopher is capable of arguing for her position, at bottom, her arguing is but rationalization, i.e., an a posteriori and necessarily incomplete justification. This leads us to suspect that the causes of our beliefs are neither fully rational, nor even transparent to ourselves- and this too must apply to Skepticism.

Thus, Sextus' argument is not limited to deductive chains of reasons, but questions the very standard used as a criterion of justification. "Now, since we cannot say on the basis of agreement by what the proof itself can be judged (for we are still investigating the standard by which) we shall not be able to decide the proof; and for this reason we shall not be able to prove the standard with which our account is now concerned" ( $P H$. II 34). Thus, even if a theorem $\mathrm{T}$ is sufficiently demonstrated within an axiomatic system $\mathrm{A}$, one would still have to justify at a meta-level the choice of this system, i.e., justify the very standards axiomatic A admits and within which T is justified; at this level it is not sufficient to show that the system is consistent. But a further justification cannot be provided (neither within axiomatic A nor by appeal to some other one) without begging the question. In these conditions, the surprising consequence is that the candidate who is most likely to be able to justify her allegiance to a philosophical "movement" is the Skeptic.

The difference between Dogmatism and Skepticism is the difference that separates giving one's assent to claims about a reality that does not appear (the Dogmatist) and giving one's assent to appearances in a skeptical manner (the Skeptic). "We say then that the standards of the skeptical movement is what is apparent [to phainomenon], meaning 
by this the impression [phantasian]; for this depends on passive and involuntary affections and it is not object of investigation" ( $P H$. I 22). From that vantage point, the Skeptic has at least the benefit of a relative justification. As Sextus construes it, assent is given to what imposes itself upon our judgment: "We do yield to things which passively move us and lead us necessarily to assent" ( $P H$. I 193). Assent, under the conditions of Skepticism, is not a choice but a compulsion that one experiences before an appearance and only insofar as it is an appearance. This condition is crucial for it indicates that although the Skeptic acknowledges a compulsion when she gives her assent, she also actively refrains from any doctrinal pronouncement concerning the nature of these appearances. By contrast, in the case of antinomies concerning what is non-appearing nothing compels us and any assent is ultimately unjustified. This means that the Dogmatist must constantly repress the haunting possibility that her beliefs could be false, no matter how well she defends them; indeed, all her argumentative skills are at the service of this goal. Yet, the looming threat of being in the wrong is not easily lifted and the tremendous efforts of justification and self-justification deployed by the Dogmatist to alleviate it can only lead to further anxiety.

As we suggested earlier, the practice of suspending judgment is an ethical act, not just as an epistemological stance. The Skeptic's way is a form of life and by living it she cannot avoid presenting it, if not as a model to emulate, at least as a possible ethos worth trying. Initially at least, the proto-Skeptic was guided (as her fellow dogmatic philosophers) by the desire to attain ataraxia.

Up to now the goal of the Skeptic is freedom from disturbance in matters of opinion and moderation of feeling in inescapable matters. For Skeptics began to do philosophy in order to decide among impressions and to ascertain which are true and which are false, so as to reach freedom from disturbance; but they came upon equipollent dispute, and being unable to decide on this, they suspended judgment. And when they suspended judgment, freedom from disturbance in matters of opinion followed fortuitously [tuchikōs] (PH. I 25-26).

This is the story of a failed attempt that nevertheless led to a discovery. The protoSkeptic had a goal. Does the Skeptic still have one? The question raises two problems: first, a goal is something that is believed to be objectively good; but, as a commentator puts it: "if Skepticism has a goal it must accept a claim that declares the nature of something to be such and such" (Grgic 2006: 142). ${ }^{17}$ Second, Sextus appeals to a definition of the goal that is borrowed from Dogmatism: "A goal (telos) is that for the sake of which everything is done or considered, while it is not itself done or considered for the sake of anything else. Or: a goal is the final object of desire" (PH. I 25). Since Sextus' text should be read as a descriptive account, the claim according to which ataraxia is the goal should

\footnotetext{
${ }^{17}$ This question has been the object of important debates. I can only consider it briefly and insofar as it relates to the focus of this essay.
} 
be understood as the statement of an initial appearance (Grgic 20o6: 145). To claim that ataraxia is desirable is to describe how things appeared to the Skeptic when she engaged in philosophy in the first place. Insofar as it is meant to be descriptive and insofar as description is opposed to determination (horizein),${ }^{18}$ the three constitutive moments of Skepticism remain open to the possibility of being themselves suspended. After all, it is puzzlement over conflicting appearances that led to disturbance and, initially at least, the quest for settling these conflicts by discovering the truth about them was assumed to be the means through which freedom from disturbance could arise. If the goal cannot be ascertained, it must have had some initial plausibility. Thus, the starting point that identifies a goal need not be a dogmatic assertion but rather an initial assumption, one that, furthermore, is not original but was shared by most Hellenistic philosophers. From this point on, however, Skepticism follows its own path, since a breakthrough actually cancels this initial hypothesis:

For those who hold the belief that things are good or bad by nature are perpetually troubled. When they lack what they believe to be good, they take themselves to be tormented by things that are bad by nature and they pursue what (or so they think) is good. And when they have acquired these things, they experience more troubles; for they are elated beyond reason and measure, and in fear things might change, they do anything so as not to lose what they believe to be $\operatorname{good}(P H . \mathrm{I} 27)$.

In the course of her investigation the Skeptic discovers that philosophy itself is the disease for which it is supposed to be the cure. ${ }^{19}$ This reversal constitutes the core of Skepticism; it is a thought no Dogmatist could entertain. And yet, it does not cancel the philosophical quest. The search for truth is compatible with the practice of epoch $\bar{e}$ because she who suspends her judgment does not claim, as the members of the New Academy allegedly did, that everything is inapprehensible. ${ }^{20}$ Thus, epoche is not a withdrawal in silence or a stubborn refusal to articulate something meaningful. Skepticism is a dialectical practice performed in the here and now of investigation. As Sextus mentions, equipollence must be "brought about;" this requires special argumentative strategies. Thus, Numenius complains that the Skeptic employs epochē to shroud herself in a "cloud of ink" (Kahn 2001: 120) i.e., she attempts to vanish, as it were, behind her own arguments. This ironic analogy with a squid was obviously reproachful, but it also reveals that

18 "Determining we deem to be not merely saying something but making an utterance about an unclear object and assenting to it. For in this sense, Skeptics will perhaps be found to determine nothing. Not even 'I determine nothing itself.' For this is not a dogmatic supposition but a phrase which shows our feeling” ( $P H$. I 197).

${ }^{19}$ Although this formulation is often believed to belong to Wittgenstein, its attribution, as far as I know, remains disputed.

20 "The members of the New Academy, if they say that everything is inapprehensible, no doubt differ from the Skeptics precisely in saying that everything is inapprehensible. For they make affirmations about this, while the Skeptic expects it to be possible for some things actually to be apprehended." (PH. I 226). 
epochē calls for a self-referential logic whereby Skepticism erases itself. In principle, all skeptical statements contain within themselves the possibility of their own annulment. Despite its occasional playfulness, Skepticism purposefully leads us to confront undecidable claims. Sextus' text contains multiple instances of this. Since the critiques deployed against dogmatism must eventually be applied to Skepticism itself, Sextus, as Wersinger and Perceau (2010: 36) have noticed, often presents us with "pragmatic contradictions" i.e., contradictions that occur between the act of saying and what is being said. The most flagrant instance occurs in the main part of Book II where, after having demonstrated the unsoundness of arguments, Sextus eliminates the arguments he appealed to establish his claim. As he puts it, skeptical formulae have "the ability (dunamis) of circumscribing themselves in order to suppress themselves" $\left(M_{7}, 206\right)$. In so doing the Skeptic does not undermine her ability to speak and think; rather, she performatively demonstrates epoche by displaying epistemic paradoxes. While an analytic contradiction would cancel the Skeptic's discourse, Sextus' strategy of self-cancellation avoids self-refutation by applying to himself his limiting skeptical clauses. "In the case of all the skeptical phrases, you should understand that we do not affirm definitely that they are true- after all, we say that they can be destroyed by themselves, being cancelled along with what they are applied to, just as purgative drugs do not merely drain the humours from the body but drive themselves out too along with the humours" (PH. I 206). Thus, when Sextus pronounces that "all is indeterminate," we should understand: "[the claim] 'all is indeterminate' is [itself] indeterminate" (Wersinger and Perceau 2010: 38 ). ${ }^{21}$ Instead of constituting a result, epoche is a response that reiterates a suspensive "perhaps."

\section{The Two Planes of the Skeptic Consciousness}

Yet, the emergence of ataraxia out of all this remains mysterious: why should one experience freedom from disturbance rather than Faustian despair? If we grant that philosophy has failed to provide the wisdom it promised, how can we find solace in this situation? When Faust, after having studied philosophy, jurisprudence, medicine, and theology (the four faculties of medieval universities) confesses his enduring ignorance, the result is not freedom from disturbance but torment. In Goethe's words:

But then, all delight for me is shattered;

I do not pretend to worthwhile knowledge,

Don't flatter myself I can teach in college

How men might be converted or bettered

(Faust, Part I, v. 370-373).

${ }^{21}$ The authors suggest that Sextus uses what they dub an "undecided modality of enunciation" (as when we say, for instance, "I am wondering if....”). 
How can tranquility arise from an acknowledged failure? Furthermore, if ataraxia can be attained without wisdom why keep the inquiry open? We usually keep trying so long as we have not attained the goal we were seeking; yet, on Sextus' account, the full-fledged Skeptic achieves ataraxia. To resolve this conundrum, the purpose of the inquiry (truth and wisdom) must be disconnected from the initial goal (freedom from disturbance). The Skeptic' discovery is that ataraxia can be attained by other means. On the one hand, from the fact that we have not found wisdom, we have no right to assert that wisdom cannot be found; hence, it is appropriate to keep the inquiry open. In fact it is the Dogmatist- not the Skeptic- who wishes to close the inquiry. Furthermore, if ataraxia does not need the attainment of wisdom, it is not the result of epoche either; rather, it occurs alongside epoche while the inquiry persists. What then connects the second moment of Skepticism (epochē) to the third one (ataraxia)?

This issue engages the very meaning of Skepticism, as indicates the fact that Sextus conflates the account of this transition with the account of how some "thinkers of old" became Skeptics. ${ }^{22}$ Thus, an answer to the question: "How do we move from epoche to ataraxia?" must contain an answer to the question "What is Skepticism?” Yet, Sextus explanation, the story of Apelles, is far from obvious.

A story told of the painter Apelles applies to the Skeptics. They say that he was painting a horse and wanted to represent in his picture the lather on the horse's mouth; but he was so unsuccessful that he gave up; took the sponge on which he had been wiping off the colors from his brush, and flung it at the picture. And when it hit the picture, it produced a representation of the horse's lather. Now the Skeptics were hoping to acquire freedom from disturbance by deciding the anomalies in what appears and is thought of, and being unable to do this they suspended judgment. But when they suspended judgment, freedom from disturbance followed as it were fortuitously [tuchikōs], as a shadow follows a body" (P.H. I 28-29).

The story engages the coherence of Skepticism. One might suppose that Apelles reaches the goal by not striving for it anymore and that, likewise, the Skeptic finds freedom from disturbance when she no longer pursues the truth. The goal is obtained by giving up the assumed means to reach it. Apelles initially assumed that it was by mastery of his technique that he would attain the effect he was striving for; similarly, the protoSkeptic, at the beginning of her investigation, believed that she would enjoy ataraxia only when she discovers the final truth about the non-appearing nature. ${ }^{23}$ The common

${ }^{22}$ This point is also noted by Bredo Johnsen (2001: 530): "Sextus' account of how it was discovered that epoche yields ataraxia is an account of how certain thinkers... became Pyrrhonists, not an account of how some thinkers who were already settled Pyrrhonists made that discovery".

${ }^{23}$ There is a temporal dimension to Sextus' narrative that suggests a chronological difference between the Skeptic entering philosophy (i.e., the proto-Skeptic) and the full-fledged Skeptic. This temporal development has been noticed by Grgic and Brennan. As Brennan (1999: 98) puts it: "In respect to one belief at least, the proto-Skeptic and the Skeptic must differ. And this will be precisely that second order belief, that one must grasp the truth before one can become tranquil, which the proto-Skeptic believed and the Skeptic no longer does". 
interpretation of the tale is, to borrow, among others, Hadot's (2002: 143) formulation that "just as Apelles was able to achieve perfection in art by renouncing art, so the Skeptic was able to realize the philosophical work of art- that is peace of mind- by renouncing philosophy in the sense of philosophical discourse". ${ }^{24}$

On closer examination, however, this does not fit with what the story is supposed to illustrate. Analogically, epoche is to the Skeptic what throwing the sponge is to Apelles. The story tells us that Apelles was frustrated, that he discovered a solution by chance, but not that he abandoned painting. Similarly, Sextus cannot suggest that we should give up the search, since this would go against the stated function and purpose of Skepticism (indeed, the very meaning of the word). A Skeptic does not throw the sponge; Apelles does not abandon painting; rather, he abandons the usual method (the brushes). The point of Skepticism is not to reach the goal by giving up the inquiry, but to reach the goal while keeping the inquiry open ("the Skeptics are still investigating" I 2).

Sextus places us in a strange position: the story of Apelles is the main clue that could explain the link between ataraxia and epoche but this very story does not allow us to extract a practical rule that could be presented as the skeptical precept on how to cure human woe. The Skeptic suspends belief about every dogmatic claim she has encountered so far. As Sextus puts it: “The phrases 'I have no apprehension' and 'I do not apprehend' show the Skeptic's own feelings, in virtue of which he refrains, for the moment, from positing or rejecting any of the unclear matters being investigated" (I 201). The two conditions: (a) it is the expression of the inquirer's pathos and (b) it has only provisional (not definitive) validity, remind us that we are reading a report, not a recipe.

What happened to Apelles in this incident changed him. Likewise, the Skeptic undergoes a transformation. Before epoche , she assumed that she would experience freedom from disturbance only if she could attain sophia and reach an ultimate insight into what is non-apparent; afterwards, she finds out that she can experience ataraxia without it. Burnyeat (1983: 139) objects to this that "ataraxia is hardly to be attained if he [the Skeptic] is not in some sense satisfied- so far- that no answers are forthcoming, that contrary claims are indeed equal". On Burnyeat's view, the Skeptic's ataraxia would require some certainty (at least some stable belief) concerning the results of the inquiry; namely, that we will always find equipollence between conflicting claims so that we can be confident in our suspension of judgment. This interpretation makes two unwarranted assumptions:

(a) it maintains what Sextus denies: ataraxia can only come from having found a certainty that cancels all doubts (in this case, the certainty that there will be no certainty). (b) It

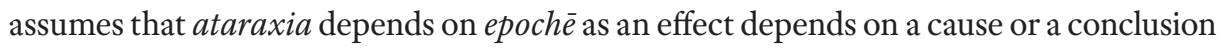
on an antecedent premise. The first assumption sees ataraxia as some permanent state,

\footnotetext{
${ }^{24}$ A similar interpretation can be found among many other commentators. For instance, Striker's interpretation of Apelles concludes: "so for the Skeptic, tranquility follows unexpectedly, not upon the discovery of truth, but upon giving up the search." (Striker 2201: 118 emphasis added). On her reading, "philosophical investigations seem to be precisely what the Skeptic's way of life is designed to avoid" (Striker 2201: 121). Richard Bett (2011: 7) writes: "the skeptic achieves his aim, ataraxia by giving up on the search for truth".
} 
a serenity that would be disturbed should it turn out that equipollence cannot be guaranteed. The Skeptic enjoys a profound satisfaction and release from prior anxiety, something akin to Apelles' surprise when he discovered a way of creating a visual impression of the lather on the horse's mouth. However, Sextus' repeated temporal conditions ("so far," "up to now," "for the moment"...) suggest that this experience is hopefully repeatable not that it requires an everlasting bliss. The second assumption, as we saw, reads in the connector "afterwards" [to de meta touto] that links epoche to ataraxia more than what Sextus can and does say. The Skeptic's transformation did not occur on the basis of some argument and it does not call for a refutation of her prior conjecture. Wisdom could still lead us to freedom from disturbance. This path is not ruled out; rather, it remains so far undecided. The search for truth and the enjoyment of ataraxia are simply not linked by conditional necessity anymore. In fact, if it is possible to experience ataraxia without having discovered any ultimate truth; and if it is so one can suspect, conversely, that such a knowledge (should it be attained) would not necessarily lead us to ataraxia.

No doubt, the Skeptic must retain a minimal conception of the goal and the good throughout her efforts, ${ }^{25}$ but we cannot say that the suspension of judgment occurs for the sake of achieving ataraxia, just as Apelles did not throw the sponge for the sake of creating the effect he was seeking. The analogy indicated by the expression: "tranquility followed as it were fortuitously, as a shadow follows a body" does not express a causal relation between body and shadow but rather stresses their simultaneity. Taken rigorously, the analogy is somewhat inadequate since, if all conditions are met (i.e., an opaque body and a source of light) a shadow cannot fail to appear whereas Sextus can only describe how ataraxia was met by the Skeptic but not assure us that this method necessarily yield the desired result. Fortuitousness disjoins cause and effect: the body is not here for the sake of creating a shadow anymore than the sponge was thrown for the sake of creating the likeness of foam. At best then, epoche provides an occasion; it opens up a space where freedom from disturbance may occur, not one where it must occur. ${ }^{26}$

There is no skeptical teaching on ataraxia and there cannot be one, since the point is to show that it can be brought about by something other than by adherence to a doctrine. The story of Apelles suggests what I would call a wandering motive in the practice of Skepticism. To wander is to drift from one point to another in such a way that the wanderer finds herself in a place she wasn't seeking. A wanderer does not move toward a determinate direction but engages in meandering. Similarly the skeptical inquirer is a wanderer who explores all manners of thinking, all sorts of arguments and beliefs without embracing any particular one, but without denying either that one might eventually be the truth the Dogmatist longs for. This musing is accompanied by ataraxia. The paradoxical thing about Apelles' story is that while the goal is eventually achieved, it is achieved without

\footnotetext{
${ }^{25}$ As noted by Grgic (2006: 150).

${ }^{26}$ Such an "occasion," it can be argued, retains a minimal form of causality; if epochē does not produce ataraxia it still remains that to place ourselves in the condition of epochē is to make ourselves receptive to ataraxia.
} 
intention. The artist did not throw the sponge in order to achieve a particular goal. Rather, as it sometimes occurs, what is most admired about a work of art came about fortuitously. Apelles was lucky, and luck is chance that ironically imitates technique. ${ }^{27}$ Instead of positing a causal or an inferential relation between epoche and ataraxia, the story of Apelles disconnects the moments of Skepticism but it also indicates that two distinct planes can coincide in our consciousness. ${ }^{28}$ Whereas a traveler organizes her journey in order to reach a pre-established destination, the full-fledged Skeptic is an explorer who has found that it is possible to continue the search, to pursue the journey, and simultaneously to experience ataraxia. Epochē is on par with a continued search for truth since the suspension of judgment does not claim that judgment is impossible. "For the latter [Dogmatists] the investigation has already reached its end, as they suppose, but for the former [Pyrrhonists] the reason why any investigation is undertaken- namely, the thought that they have not made a discovery- still remains" (PH. II 11). This situation leads the Skeptics to give to inquiry a higher status than the Dogmatists or the Academics do. In accord with Socrates, the consciousness of not knowing is what enables inquiry, not what hinders it.

As an analogue for the narrative account of the path to Skepticism, the story of Apelles illustrates a transformation. The unintended effect of epoche is to relieve the inquirer from the emotional attachment she had for her cherished beliefs. Some commentators have objected that the Skeptic is disingenuous. ${ }^{29}$ One could wonder why a condition of no belief would lead to tranquility..$^{\circ}$ And furthermore, if the goal remains the attainment of ataraxia and if it turns out that it can be achieved independently from complete knowledge, why keep seeking the truth? As we argued earlier, the transformation the Skeptic underwent allows her to experience ataraxia without assuming that ultimate knowledge is its precondition; but this, instead of entailing a rejection of philosophy, transforms its practice. If, for the Skeptic, philosophy is first and foremost inquiry, its value cannot dependent on securing a truth which, in turns, would become the condition

${ }^{27}$ On the relation between luck and technē see Massie (2003).

${ }^{28}$ Perin (2006: 345) also notices this point: "If, therefore, the story of Apelles is supposed to reveal something about the relation between the Pyrrhonist's suspension of judgment and her tranquility, it is that the Pyrrhonist does not suspend judgment in order to achieve tranquility".

${ }^{29}$ As Perin (2010: 9) puts it: "the Sceptic is and must be someone who is not engaged in the search for truth. In addition, the Sceptic deploys instances of certain argument-schemas-the so-called Agrippan modes-that collectively purport to show that no one can have any reason to believe anything. But the use of arguments with this negative dogmatic conclusion seems to be incompatible with the search for truth. For someone is genuinely engaged in the search for the truth about some matter only if she does not deny that it is possible to discover the truth about that matter". Perin then must assume that Sextus is a crypto-Academic despite Sextus explicit contention that Academic philosophy is a form of dogmatism and despite the fact that it falls repeatedly under his critique. I find this assumption implausible. Sextus' strategy is much more subtle than Perin assumes. The postponement of the truth (which is needed in order to keep the inquiry open) is not identical with its denial (which Sextus avoids). As for Perin's second assumption according to which Sextus basically lies and that he is not interested in inquiry, it is disproved by the very existence of his not insignificant corpus of philosophical investigations.

${ }^{30}$ This objection is voiced by Grgic (2006: 159): “The question is why a person who wants to achieve tranquility has to bring herself to a state in which she has absolutely no belief. Unfortunately, Sextus does not provide an answer to that question". 
of ataraxia. This assumption must be cancelled for two reasons: (a) we now recognize that ataraxia can be experienced without enlightenment and (b) whether human beings will eventually attain enlightenment at some future point remains fundamentally undecided. Thus, in the compound word "philo-sophia" the Skeptic stresses the first part: the inquisitive activity of the desiring intellect is itself valuable. Thereby, Sextus commits philosophy to be infinite inquiry, a philein seeking a constantly postponed sophia; but to do this the possibility of achieving sophia must remain undecided, even undecidable; declaring it already achieved or unachievable would, on the contrary, abolish philosophy.

In order to keep investigating, Skepticism must uncompromisingly apply its critique to itself. Should Skepticism presume to be immune to critical scrutiny, it would rightly be accused of taking a Dogmatic stand to which it is not entitled.

Just as it is not impossible for the man who has ascended to a high place by a ladder to overturn the ladder with his foot after his ascent so also it is not unlikely that the Skeptic, after he has arrived at the demonstration of his thesis by means of the arguments proving the nonexistence of proof, as it were by a step-ladder, should then abolish (anelein) this very argument" $(M, 8,481)^{31}$.

By kicking the step-ladder the Skeptic does not quite fall back to her initial starting point. As Castagnoli has shown, Sextus' strategy does not lead to self-contradiction. The terms perigraphein and sumperigraphein, which Sextus reserves to describe what happens when the skeptical method is applied to skeptical arguments themselves, do not suggest a process of self-refutation (which would entail that what has been said is false) but rather indicate an act of cancellation, or "self-bracketing" as Castagnoli puts it. ${ }^{32}$ The purpose of this paradoxical self-cancellation is to induce epoche which is valued for its therapeutic function. Ultimately, the value of philosophy is something the Skeptic can only show by performing it: the very existence of the Sextan corpus is its demonstration. This unrelenting thirst of inquiry that sustains philosophical investigation upholds neither that sophia is the means to tranquility nor that philosophy will eventually end in the final revelation of the truth. None of these are impossible, but none are necessary.

The difference between planes of consciousness becomes manifests when we distinguish two phenomena that are often confused because they are experienced concurrently; namely, inclination and belief. The first (inclination) acknowledges an appearance, ${ }^{33}$

\footnotetext{
${ }^{31}$ Besides the analogy with the purgative medicine which, after eliminating the humors, must eliminate itself, Sextus offers a third analogy with fire which "after consuming the fuel destroys also itself.... So too the argument against proof, after abolishing every proof, can cancel itself also" $(M .8,480)$.

32 "Sextus never accepts, and so much the less embraces, the dogmatic charge of self-refutation; what is interpreted [...] as an admission of self-refutation is best reconstructed as a refined dialectical tool that Sextus uses against the dogmatist charges of inconsistency and self-refutation" (Castagnoli 2010: 252).

33 "We do not overturns anything which leads us, without our willing it, to assent in accordance with a passive appearance- and these things are precisely what is apparent" (PH. I 19).
} 
while the second (belief) affirms a reality. To practice epochē is to accustom oneself to dissociate these moments. Although a belief entails an inclination, the converse is not true. It is not inconsistent to say "I am inclined to believe that p" or "it appears to me that p" and, simultaneously, to maintain "I do not believe that p." ${ }^{34}$ In other words, the partition is not between belief and no belief, but between believing in a dogmatic sense (i.e., making alethic claims) and believing in a skeptical sense (i.e., acknowledging an inclination generated by an appearance). The subject of the first two above-mentioned sentences ("I am inclined to believe that p" and "it appears to me that p") is the speaker herself. These assertions do not address the nature of $\mathrm{p}$; they refer to appearances insofar as they appear to me. "An appearance, then, will actually be of the feeling of a sense [tou pathous tēs aisthēseōs]- and that is different from an external existing object" ( $P H$. II 72). The crucial characteristic of appearances, according to Sextus, is that appearances are involuntary. However, the acknowledgment that something appears and that one experiences an inclination to believe do not compel the Skeptic to claim that what she is inclined to believe is actually true. In the third sentence ("I do not believe that p") "p" stands for a thetic belief, i.e., a claim about the nature of that toward which the Skeptic experiences an inclination. Acknowledging an inclination and making a dogmatic claim are not identical and it is because the Skeptic is conscious of the difference between being inclined to believe and actually believing, or between acknowledging an appearance and upholding its truth that those who have criticized the Skeptics either for having no beliefs or for having beliefs when they should not have missed the point on both counts. This is reflected in Sextus' own writing strategies. Most of the Outlines follow the method of elenchus and focus on the critical evaluation of dogmatic claims and objections. When, however, Sextus composes what we could call an argument in favor of Skepticism, he systematically frames it as a report on how things appear to the Skeptic and avoids any thetic claim by applying self-cancellation to his own account.

The issue, however, is not exclusively epistemological. To the distinction between "inclination/appearance" and "belief/non-apparent reality" corresponds a difference in the inquirer's ethos. To become a Skeptic is to undergo a conversion, even though this conversion cannot be confused with the enlightenment of a sage who has contemplated the truth. The Skeptic is a changed person because she has learned to dissociate herself from the many thoughts she entertains. ${ }^{35}$ An inner doubling has occurred; the Skeptic detaches herself from her beliefs, noticing how things appear to her, observing how she finds herself inclined to accept some appearances, while remaining on another plane mindful not to let herself make any dogmatic claim. Sextus insists on many occasions that appearances (i.e., the unmediated and involuntary objects of consciousness), are the Skeptic's own appearances. She can acknowledge her mental inclinations without

\footnotetext{
34 This compatibility is also acknowledged by Johnsen (2001: 552).

${ }^{35}$ As McPherran (1989:169) puts it: "a Skeptic will hold that he experiences himself as a center of consciousness distinguishable from his 'organ of rationality,' conceived of along the lines of his other bodily organs”.
} 
being committed to a corresponding dogmatic belief because she has become a surveyor of her own thoughts, an observer of her own consciousness. In that sense, the Skeptic's transformative discovery is also self-discovery; it is the realization that the conscious self is distinct from consciousness' intentional content. ${ }^{36}$ To express it in the language of Husserl's phenomenology, pure (transcendental) consciousness is established by a method of bracketing (epochē) empirical data and particular beliefs away from consideration. In a similar fashion, the Skeptic has discovered a space that opens a distance between herself and the thoughts she entertains. It is because she can hold her thoughts at a distance that she is capable of engaging in their critical examination in the first place, something that proves especially difficult, if not impossible, for a Dogmatist. This is the point where epistemological, psychological, and ethical concerns coincide and it in this space of play, in this leeway, that ataraxia can emerge.

${ }^{36}$ Some have noted a parallel with Buddhism, for instance Adrian Kuzminski (2008: 95) writes: “The liberation from suffering promoted by both Buddhists and Pyrrhonists depends crucially on distinguishing between consciousness and the objects of consciousness". 


\section{BIBLIOGRAPHY}

\section{ANCIENT SOURCES}

SeXtus EmpIricus, Outlines of Skepticism, ed. J. Annas \& J. Barnes, Cambridge $2000^{2}$.

Sextus Empiricus, Outlines of Pyrrhonism. Against the logicians. Against the physicists, Against the ethicists. Against the professors, ed. R. G. Bury, vol. I-IV, Cambridge MA 1933-1949.

Diogenes LAERTius, Lives of Eminent Philosophers, ed. R. D. Hicks, Cambridge MA 1925.

\section{MODERN SOURCES}

BAILEY, A., 2002, Sextus Empiricus and Pyrrhonean Scepticism, Oxford.

Betr, R., 2011, “How Ethical Can an Ancient Skeptic Be?”, in D. Machuca (ed.), Pyrrhonism in Ancient, Modern, and Contemporary Philosophy, Dordrecht, pp. 3-18.

Brennan, T., 1999, Ethics and Epistemology in Sextus Empiricus, New York/London.

Burnyeat, M., 1980, “Can the Sceptic Live His Scepticism?” in: Burnyeat, Frede (1997), pp. 25-57.

Burnyeat, M., Frede, M., 1997, The original Sceptics: A Controversy, Indianapolis, IN.

Castagnoli, L., 2010, Ancient Self-Refutation: The Logic and History of the Self-Refutation Argument from Democritus to Augustine, Cambridge.

Goethe, J. W., 2001, Faust, A Tragedy, translated by W. Arndt, New York.

Grgic, F., 2006, "Sextus Empiricus on the Goal of Skepticism," Ancient Philosophy 26, pp. 141-160.

HADot, P., 2002, What is Ancient Philosophy?, Cambridge, MA.

Johnsen, B., 2001, “On the Coherence of Pyrrhonean Skepticism,” Philosophical Review, 110, pp. 521-561.

KAHN, C., 2001, Pythagoras and the Pythagoreans, A brief History, Indianapolis IN.

KuZMinski, A., 2008, Pyrrhonism: How the Ancient Greeks Reinvented Buddhism, Lanham.

Laursen, J. C., 2009, "Skepticism and Cynicism in the Work of Pedro de Valencia," in J. R. Maia Neto, G. Paganini, J. C. Laursen (eds.), Skepticism in the Modern Age: Building on the Work of Richard Popkin. Leiden, pp. 139-158.

Massie, P., 2003, “The Irony of Chance: On Aristotle Physics B 4-6,” International Philosophical Quarterly 43, pp. 15-28.

MCPherran, M., 1989, “Ataraxia and Eudaimonia in Ancient Pyrrhonism: Is the Skeptic Really Happy?”, Proceedings of the Boston Area Colloquium in Ancient Philosophy 5, pp. 135-171.

Perin, C., 2006, "Pyrrhonian Scepticism and the Search for Truth,” Oxford Studies in Ancient Philosophy 30, pp. $337-360$.

PERIN, C., 2010, The Demands of Reason, an Essay on Pyrrhonian Scepticism, Oxford.

Stough, C., 1984, “Sextus Empiricus on Non-Assertions,” Phronesis 29, pp. 137-164.

STriker, G., 2001, "Scepticism as a Kind of Philosophy," Achiv für Geschichte der Philosophie 83, pp. 113-129.

Vogt, K. M., 2010, “Scepticism and Action,” in R. Bett (ed.), Cambridge Companion to Ancient Scepticism, Cambridge, pp. 165-180.

Vogt, K. M., 2012, “Appearances and Assent, Sceptical Belief Reconsidered.” The Classical Quarterly 62, pp. 648-663.

Wersinger, A. G., Perceau, S., 2010, “L'auto-réfutation du Sceptique vue de la scène antique” Revue de Métaphysique et de Morale 65, pp. 25-43. 
PASCAL MASSIE

/ Oxford, $\mathrm{OH} /$

K EY WOR D S

\section{Philosophy and Ataraxia in Sextus Empiricus}

This essay addresses two interconnected questions: (a) In what sense is Skepticism a philosophy? (b) How can ataraxia emerge out of epochē? Skepticism is a practice that articulates three moments: equipollence, epochē (suspension of judgment), and ataraxia (freedom from disturbance) and Sextus' account of how one can move through these moments demonstrates the its philosophical nature. However, to clarify the transition from epoche to ataraxia Sextus offers only one clue: the story of Apelles. If this story is paradigmatic, it is also ambiguous since the transition from epoche to ataraxia can neither be causal nor inferential. Apelles achieves his goal purely by chance. Contrary to a common interpretation, this doesn't mean that the Skeptic abandons the inquiry (just as Apelles doesn't abandon painting). Lastly, the essay argues that Skepticism is not only the practice of a certain dialectical method but also a practice upon oneself. The Skeptic must learn to dissociate herself from the thoughts she entertains. Sustained inquiry can coexist with ataraxia because the Skeptic has discovered that her consciousness is distinct from its intentional content now bracketed by epoche . To free ourselves from our attachment to dogmatic beliefs is to opens up a space of self-detachment.

Sextus Empiricus, Skepticism, epochē, ataraxia, Apelles 